Fetal Diagnosis aud Therapy
Fetal Diagn Ther 2014;35:204-211

DOI: $10.1159 / 000356495$
Received: September 12, 2013

Accepted after revision: October 21, 2013

Published online: November 15, 2013

\title{
Cell-Free DNA Analysis for Trisomy Risk Assessment in First-Trimester Twin Pregnancies
}

\author{
Maria del Mar Gil Maria Soledad Quezada Barbara Bregant Argyro Syngelaki \\ Kypros H. Nicolaides \\ Harris Birthright Research Centre of Fetal Medicine, King's College Hospital, London, UK
}

\section{Key Words \\ Non-invasive prenatal testing · Trisomy $21 \cdot$ Fetal \\ aneuploidy $\cdot$ Twin pregnancy $\cdot$ First-trimester screening}

\begin{abstract}
Objective: To examine the clinical implementation of chromosome-selective sequencing of cell-free DNA (cfDNA) in maternal blood and an algorithm that relies on the lower fetal fraction contribution of the 2 fetuses in the assessment of risk for trisomies in twin pregnancies. Methods: Risk for trisomies 21, 18 and 13 by cfDNA testing were estimated in stored plasma samples obtained at 11-13 weeks' gestation from 207 pregnancies with known outcome and prospectively in 68 twin pregnancies undergoing screening at 10-13 weeks. Results: Risk scores for trisomies were provided for 192 (92.8\%) of stored plasma and for 63 (92.6\%) of the prospective cases. In the retrospective study, 10 of 11 trisomic pregnancies were correctly identified with no false positive results. In the prospective study, 3 trisomic pregnancies were correctly identified with no false positive results. The median of the lower fetal fraction in the prospective study of twins was 7.4\% (IQR range 5.9-10.0\%), which was lower than in our previous study in singletons (median 10.0\%, IQR 7.813.0\%). Conclusions: cfDNA testing in twins is feasible but the reporting rate of results is lower than in singletons due to a lower fetal fraction.

(c) 2013 S. Karger AG, Basel
\end{abstract}

\section{Introduction}

In singleton pregnancies, cell-free DNA (cfDNA) testing in maternal blood can detect about $99 \%$ of cases of trisomy 21 , about $97 \%$ of trisomy 18 and $92 \%$ of trisomy 13 , with respective false positive rates of $<0.1,<0.2$ and $0.2 \%$ [1]. In cfDNA testing the ability to detect the small increase in the amount of a given chromosome in maternal plasma in a trisomic compared to a disomic pregnancy is directly related to the relative proportion of the fetal to maternal origin of the cfDNA. When the fetal fraction is low, it is more difficult to discriminate between aneuploid and euploid pregnancies and a minimum fraction of about $4 \%$ is currently necessary for accurate cfDNA analysis [2-6].

In twin pregnancies, cfDNA testing is more complex than in singleton pregnancies because the 2 fetuses could be either monozygotic, which are therefore genetically identical, or dizygotic, in which case only 1 fetus is likely to have aneuploidy when present. There is evidence that in dizygotic twins each fetus can contribute different amounts of cfDNA into the maternal circulation, which could vary by nearly twofold $[7,8]$. It is therefore possible that in a dizygotic twin pregnancy discordant for aneuploidy, the fetal fraction of the affected fetus is below the threshold of $4 \%$ for successful cfDNA testing. This could lead to an erroneous result of

\begin{tabular}{ll}
\hline KARGER & $\begin{array}{l}\text { () 2013 S. Karger AG, Basel } \\
1015-3837 / 13 / 0353-0204 \$ 38.00 / 0 \quad \text { Karger }\end{array}$ \\
$\begin{array}{l}\text { E-Mail karger@karger.com } \\
\text { www.karger.com/fdt }\end{array}$ & $\begin{array}{l}\text { This is an Open Access article licensed under the terms of the } \\
\text { Creative Commons Attribution-NonCommercial 3.0 Un- } \\
\text { ported license (CC BY-NC) (www.karger.com/OA-license), } \\
\text { applicable to the online version of the article only. Distribu- } \\
\text { tion permitted for non-commercial purposes only. }\end{array}$
\end{tabular}

Prof. K.H. Nicolaides

Harris Birthright Research Centre for Fetal Medicine

King's College Hospital, Denmark Hill

London SE5 9RS (UK)

E-Mail kypros@fetalmedicine.com 
low risk for aneuploidy because a high contribution from the disomic co-twin could result in a satisfactory total fetal fraction. To avoid this potential mistake it was proposed that in cfDNA testing in twin pregnancies the lower fetal fraction of the 2 fetuses, rather than the total, should be estimated in the assessment of risk for aneuploidies [9].

The objective of this study is to examine the clinical implementation of chromosome-selective sequencing and an algorithm that relies on the lower fetal fraction of the twins [9] in the assessment of risk for trisomies in twin pregnancies at $10-13$ weeks' gestation.

\section{Methods}

Maternal blood cfDNA testing was undertaken in two groups of twin pregnancies: in the first group retrospectively and in the second prospectively. In both groups, gestational age was determined from the measurement of the crown-rump length (CRL) of the larger twin and chorionicity was determined by examining the inter-twin membrane at its junction with the placenta $[10,11]$. Maternal characteristics recorded were age, racial origin, smoking status during pregnancy, method of conception and weight, which was measured at the time of screening.

\section{Study on Stored Plasma Samples}

We had 207 stored plasma samples obtained at 11-13 weeks' gestation from twin pregnancies undergoing first-trimester screening for trisomies by a combination of fetal nuchal translucency thickness (NT) and maternal serum-free $\beta$-human chorionic gonadotropin ( $\beta$-hCG) and pregnancy-associated plasma protein-A (PAPP-A) [12-14]. Blood samples were collected in ethylenediaminetetraacetic acid (EDTA) BD Vacutainer ${ }^{\mathrm{TM}}$ tubes (Becton Dickinson UK Ltd, Oxford, UK) and within 15 min of collection they were centrifuged at 2,000 $\mathrm{g}$ for $10 \mathrm{~min}$ to separate plasma from packed cells and subsequently at $16,000 \mathrm{~g}$ for $10 \mathrm{~min}$ to further separate cell debris. Plasma samples were divided into 0.5$\mathrm{ml}$ aliquots in separate Eppendorf tubes which were labelled with a unique patient identifier and stored at $-80^{\circ} \mathrm{C}$ until subsequent analysis. All patients were recruited at Kings' College Hospital in London and they gave written informed consent to provide samples for research which was approved by the NHS Research Ethics Committee.

\section{Prospective Study}

This consisted of 68 twin pregnancies undergoing prospective screening for trisomies 21,18 and 13 by cfDNA testing at the Fetal Medicine Centre in London, between March and October 2013. The patients attended the clinic at 10-13 weeks' gestation, received pre-test counselling [15] and provided written consent for cfDNA testing. Maternal blood $(20 \mathrm{ml})$ was collected in Streck cfDNA BCT ${ }^{\mathrm{TM}}$ tubes. In all cases the combined test was also carried out either in the same visit, if the gestational age was 11-13 weeks, or in a subsequent visit for those presenting during the 10th week.

Cell-Free DNA Analysis in Twin

Pregnancies
Analysis of Samples

Stored plasma samples $(2 \mathrm{ml} /$ patient $)$ and prospectively collected blood samples $(20 \mathrm{ml} /$ patient $)$ were sent without any further processing via courier to the USA for cfDNA testing (Harmony ${ }^{\mathrm{TM}}$ Prenatal Test; Ariosa Diagnostics, Inc., San Jose, Calif., USA). The information given to the laboratory for each case was: patient-unique identifier, maternal age, maternal weight, method of conception and date of blood collection, but not fetal karyotype.

cfDNA was extracted from the maternal plasma or blood samples and chromosome-selective sequencing with digital analysis of selected regions (DANSR ${ }^{\mathrm{TM}}$ ) was carried out as in singleton pregnancies [16]. However, in the assessment of risk for trisomies the fetal-fraction optimized risk of trisomy evaluation (FORTE ${ }^{\mathrm{TM}}$ ) algorithm used for singletons was modified so that the smallest fetal fraction contribution of the 2 fetuses was considered [9]. Risk scores for trisomy 21,18 and 13 were provided as a percentage with ranges capped at $>99$ and $<0.01 \%$.

\section{Results}

\section{Study on Stored Plasma Samples}

The characteristics of the study population are summarized in table 1 . This group included 193 twin pregnancies with euploid fetuses (109 dichorionic and 84 monochorionic), 10 with trisomy 21 (8 dichorionic and discordant for aneuploidy, 1 dichorionic concordant for aneuploidy and 1 monochorionic), 1 with trisomy 18 and 3 with trisomy 13 (all 4 dichorionic and discordant for aneuploidy).

Risk scores for trisomies 21,18 and 13 by cfDNA testing were provided for 192 (92.8\%) of the 207 samples (table 2). In 15 dichorionic twin cases, including 1 case of trisomy 18 and 2 of trisomy 13 , no result was provided either due to low fetal fraction $(\mathrm{n}=11)$ or laboratory processing issues $(n=4)$.

In all 181 euploid cases with a result, the risk score for each trisomy was less than 1:10,000 (table 2). In all 10 cases of trisomy 21, the risk scores for trisomies 18 and 13 were less than 1:10,000 and the score for trisomy 21 was $>99 \%$ in $8,72 \%$ in 1 and $1: 714$ in 1; the last case had the lowest fetal fraction of all the trisomy 21 cases at $5.3 \%$. In the 1 case of trisomy 13 with a result, the risk score for trisomy 13 was $>99 \%$ and the scores for trisomies 21 and 18 were less than $1: 10,000$.

In the dichorionc twin pregnancy with 1 trisomy 21 and 1 euploid fetus where the cfDNA test risk score was $1: 714$, the maternal age was 38 years, serum-free $\beta$-hCG was 2.809 multiples of the median (MoM) and PAPP-A was $0.748 \mathrm{MoM}$, and the NT thickness was $8.6 \mathrm{~mm}$ for the trisomic and $2.5 \mathrm{~mm}$ for the euploid fetus. The risks from the combined test were $1: 2$ and 1:13, respectively. 
Table 1. Characteristics of the study population for cfDNA testing of stored maternal plasma samples

\begin{tabular}{|c|c|c|c|c|}
\hline Characteristic & $\begin{array}{l}\text { Euploid } \\
(\mathrm{n}=193)\end{array}$ & $\begin{array}{l}\text { Trisomy } 21 \\
(\mathrm{n}=10)\end{array}$ & $\begin{array}{l}\text { Trisomy } 18 \\
(\mathrm{n}=1)\end{array}$ & $\begin{array}{l}\text { Trisomy } 13 \\
(\mathrm{n}=3)\end{array}$ \\
\hline Maternal age, years & $33.6(29.0-36.6)$ & $36.7(34.2-37.9)$ & 41.0 & $28.3(26.7-34.5)$ \\
\hline Maternal weight, kg & $67.0(60.5-78.0)$ & $69.5(62.5-73.2)$ & 65.0 & $71.0(65.5-78.4)$ \\
\hline \multicolumn{5}{|l|}{ Racial origin } \\
\hline Caucasian & $135(69.9)$ & $8(80.0)$ & $1(100.0)$ & $1(33.3)$ \\
\hline East Asian & $1(0.5)$ & 0 & 0 & 0 \\
\hline Mixed & $9(4.7)$ & 0 & 0 & 2 \\
\hline Cigarette smoker & $13(6.7)$ & 0 & 0 & 0 \\
\hline \multicolumn{5}{|l|}{ Mode of conception } \\
\hline Spontaneous & $105(54.4)$ & $5(50.0)$ & 0 & $1(33.3)$ \\
\hline Assisted & $88(45.6)$ & $5(50.0)$ & $1(100.0)$ & $2(66.7)$ \\
\hline Free $\beta$-hCG MoM & $1.09(0.72-1.57)$ & $2.32(1.53-3.25)$ & 0.04 & $0.83(0.62-1.02)$ \\
\hline Fetal fraction, \% & $9.8(7.4-12.1)$ & $10.8(6.8-12.1)$ & - & 7 \\
\hline
\end{tabular}

Values are median (IQR) or n (\%).

Table 2. Risk scores for trisomies by cfDNA testing of maternal plasma in mono- and dichorionic twin pregnancies

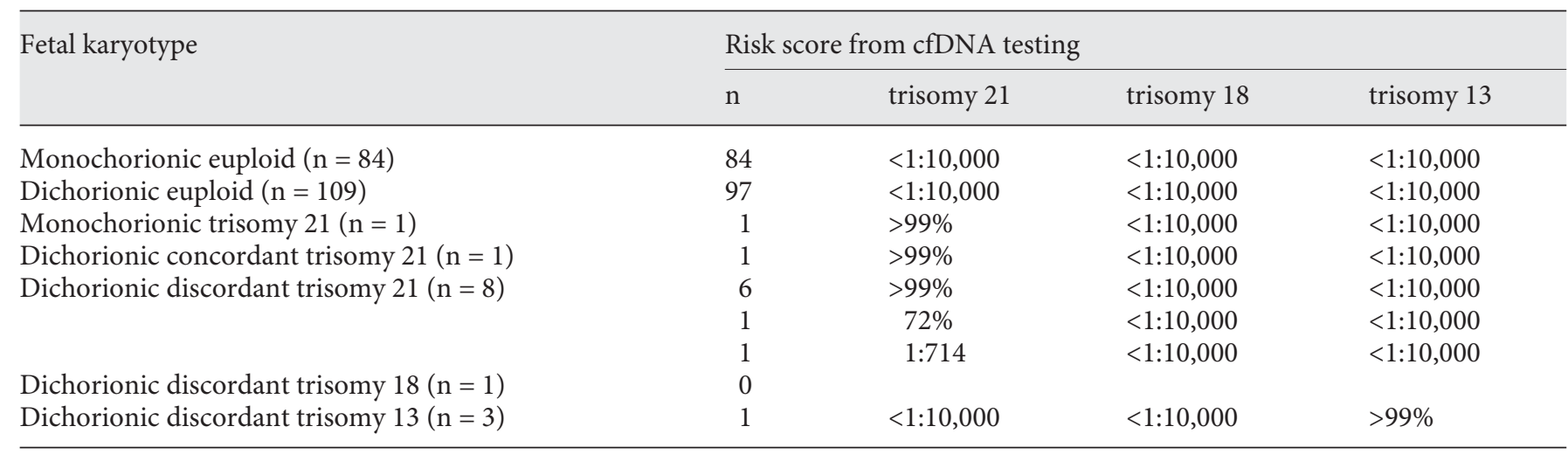

\section{Prospective Study}

The median maternal age of the study population was 37.2 (range $30.2-47.7)$ years, and $53(77.9 \%)$ were 35 years or older. The median maternal weight was 64.2 (47.0-95.7) kg. The racial origin of the women was Caucasian in $57(83.8 \%)$, South Asian in 7 (10.3\%), East Asian in $3(4.4 \%)$ and Afro-Caribbean in $1(1.5 \%)$. Conception was spontaneous in $22(32.4 \%)$ and by in vitro fertilization in 46 (67.6\%). There were 16 monochorionic and 52 dichorionic pregnancies and the median gestational age at cfDNA testing was 10.6 (range 10.0-13.9) weeks.
In the dichorionic twin pregnancies the combined test of maternal age, fetal NT and serum-free $\beta$-hCG and PAPP-A provided a risk for trisomy 21 and trisomies 18 or 13 for each fetus, whereas in monochorionic pregnancies the average risk for the 2 fetuses was provided [1114]. The risk for the 3 trisomies (highest of the 2 fetuses in dichorionic twins and average in monochorionic twins) was 1:100 or higher in 18 (26.5\%) of the 68 pregnancies (fig. 1). This is the cut-off considered by the UK National Screening Committee for classifying pregnancies as high risk. 


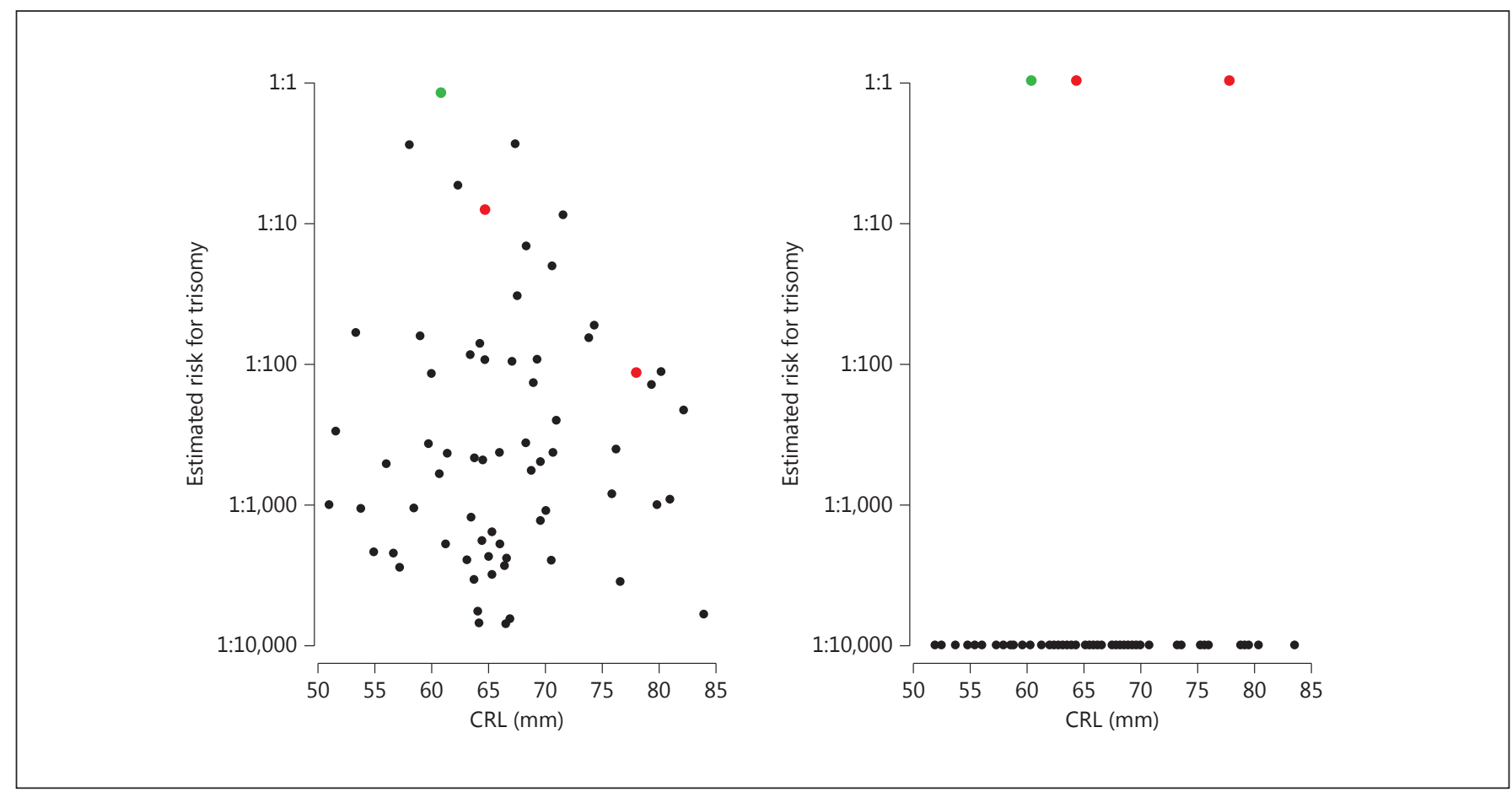

Fig. 1. Estimated risk for trisomies 21, 18 or 13 in the pregnancies with trisomy 21 (red circle), trisomy 18 (green circle) and assumed euploid (black circle) fetuses by the combined test (left) and maternal blood cfDNA test (right).

Fig. 2. Flow chart of prospective screening for trisomies 21,18 or 13 in twin pregnancies by cfDNA testing in maternal blood.

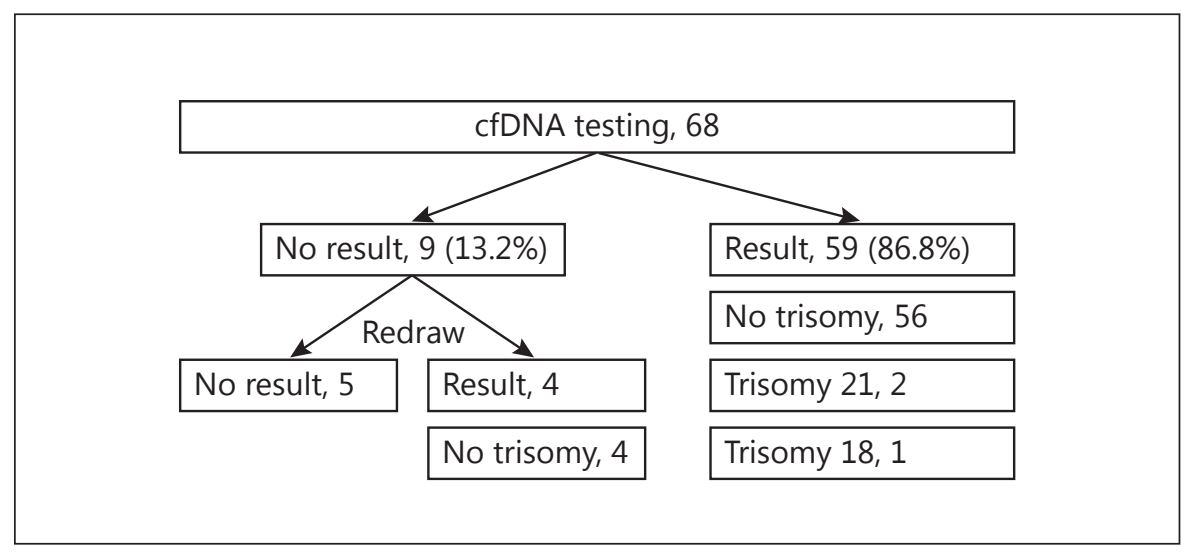

The median time interval between blood sampling and arrival of the samples to the laboratory for cfDNA testing was 2 (range 1-5) days and the interval between blood sampling and receiving results was 10 (range 7-16) days with $97.1 \%$ (66 of 68) being available within 14 days from sampling. The median lower fetal fraction was $7.4 \%$ (IQR 5.9-10.0\%).

Cell-Free DNA Analysis in Twin Pregnancies
Risk scores from cfDNA testing were provided for 59 (86.8\%) of the 68 cases (fig. 2) on the first blood draw. In 9 cases, including 8 dichorionic and 1 monochorionic, no result was provided because of low fetal fraction. In these 9 cases a further blood sample was obtained and a risk score was provided in 4 . Therefore, cfDNA results were provided for a total of $63(92.6 \%)$ cases. In 60 of the 63 cases with a result, the risk score for each of the 3 triso- 
mies 21, 18 and 13 was less than 1:10,000, in 2 the score for trisomy 21 was $>99 \%$ and the score for trisomies 18 and 13 was less than 1:10,000 and in 1 case the risk score for trisomy 18 was 59\% and the score for trisomies 21 and 13 was less than $1: 10,000$ (fig. 1).

The 60 pregnancies with risk scores for each trisomy of less than 1:10,000 are continuing except one pregnancy that has resulted in a live birth of a phenotypically normal neonate. In the 3 high-risk pregnancies, invasive testing was carried out and karyotyping confirmed the suspected trisomy in 1 of the twins for all cases. In the case of trisomy 18 and 1 of the 2 with trisomy 21 , chorionic villous sampling was performed at 13 and 14 weeks, respectively, followed by selective fetocide a few days later using ultrasound-guided injection of potassium chloride into the heart of the affected fetus; these pregnancies are now continuing normally at 27 and 22 weeks, respectively. In the second pregnancy with trisomy 21 , cfDNA testing was carried out at 13.4 weeks, the results were available at 14.7 weeks, amniocentesis was performed at 15 weeks and selective fetocide at 15.7 weeks. At 20 weeks there was preterm prelabor amniorrhexis and a few days later miscarriage of the whole pregnancy.

In the 3 cases with proven fetal aneuploidies, the risk for trisomies 21,18 or 13 by the combined test was $1: 2$, $1: 8$ and $1: 121$, respectively. In 2 of the 4 cases with no result from cfDNA testing, the risk from the combined test was $>1: 100$ and in these cases invasive testing demonstrated normal fetal karyotype.

In our study population the expected number of pregnancies with trisomy 21,18 or 13 , in at least 1 of the fetuses, on the basis of the maternal age distribution and the age-related risk for these trisomies at the 11- to 13-week scan was $2.12[17,18]$. The expected number on the basis of the combined test was 2.7 [11-14], which is similar to the observed number of 3 . On the assumption that all continuing pregnancies are normal, in the 63 cases with a cfDNA test result there were 3 trisomic and 60 unaffected pregnancies. The false positive rates were $0 \%$ for cfDNA testing and $23.3 \%$ (14 of 60 ) for the combined test.

\section{Discussion}

\section{Main Study Findings}

This study demonstrates the feasibility of chromosome-selective sequencing of cfDNA in maternal blood for the assessment of risk for fetal trisomies 21, 18 and 13 in twin pregnancies at $10-13$ weeks' gestation. In the study of stored plasma samples, a risk score was provid- ed for $93 \%$ of cases and the method correctly classified 11 of the 12 trisomic pregnancies with no false positive results. In the prospective study, risk scores for trisomies were provided for $92.6 \%$ of cases and the method correctly identified 3 trisomic pregnancies with no false positive results. The detection rate is uncertain until all pregnancies with a low-risk score have a pregnancy outcome.

\section{Result Rate and Low Fetal Fraction}

In the prospective study the rate of reporting results from chromosome-selective sequencing of cfDNA in maternal blood was $86.8 \%$ and this was improved to $92.6 \%$ after repeat sampling. These rates are considerably lower than the respective values of 95 and $98 \%$ observed in singleton pregnancies at 10 weeks' gestation using the same method of sequencing [15].

The reason for the lower reporting rate in twins was low fetal fraction and this is the inevitable consequence of selecting the lower fetal fraction of the 2 fetuses, rather than the total, in estimating the risk for aneuploidies [9]. The median of the lower fetal fraction in the prospective study of twins was 7.4\% (IQR 5.9-10.0\%), which was lower than in our previous study in singletons (median $10.0 \%$, IQR 7.8-13.0\%) [19]. The rationale for this choice is to avoid a false negative result in a dizygotic twin pregnancy discordant for aneuploidy where the total fetal fraction is satisfactory but the contribution of the affected fetus could be less than $4 \%$.

In our study of stored plasma samples there was 1 case of trisomy 21 with discordant cfDNA and invasive testing results. This case had the lowest fetal fraction of all the trisomy 21 pregnancies at $5.3 \%$ and it is the only case with a cfDNA screen-negative result where the risk score was 1:714; in all other euploid cases in the retrospective study and the presumed euploid cases in the prospective study the risk score was less than 1:10,000. This case emphasizes the importance of knowing the fetal fraction in interpreting results from any cfDNA testing method because accurate counting of the incremental cfDNA fragments from the trisomic fetus, in both singletons and twins, at low fetal fractions is reduced and thus differentiation between euploid and aneuploid is less clear. One practical option that is likely to reduce the potential for a false negative result from cfDNA testing is to rely on the results of the combined test in deciding in favour or against invasive testing when the fetal fraction is low and the risk score from cfDNA testing is higher than 1:10,000. Such cases are very uncommon and it is therefore unlikely that this policy would result in a significant increase in the rate of invasive testing. 


\section{Comparison with the Combined Test}

In our prospective study, most pregnancies are continuing and it is therefore not possible at present to assess the sensitivity of the screening tests in identifying the trisomic fetuses. However, the observed number of affected pregnancies is similar to that estimated from the maternal age distribution of the study population and the results of the combined test. On the assumption that there are no fetuses with trisomy 21,18 or 13 among the continuing pregnancies, the combined test, at the recommended risk cut-off of 1:100, identified 2 of the 3 affected pregnancies and cfDNA testing detected all 3. Other major advantages of cfDNA testing, compared to the combined test, highlighted by our study are firstly, reporting of results as a very high or very low risk which makes it easier for parents to decide in favour or against invasive testing (fig. 1) and secondly, a substantial reduction in the false positive rate.

The patients attending the Fetal Medicine Centre were self-referred and the high false positive rate of $23 \%$ from the combined test is likely to be the consequence of the high maternal age of the study population, with $78 \%$ being 35 years or older, and at least in some a high-risk result from prior screening by the combined test in their own hospital. Two thirds of the pregnancies were conceived by in vitro fertilization and these women were reluctant to undergo invasive testing.

\section{Results of Previous Studies}

Three previous studies of cfDNA testing in twins used massively parallel shotgun sequencing to assess the risk for trisomies 21, 18 and 13 [5, 20,21]. The first study examined 5 twin pregnancies, 4 in a training set and 1 in a test set, and correctly categorized the 2 with trisomy 21 fetuses (both in the training set) and the 3 with euploid fetuses [5]. The second study examined stored plasma samples from 25 twin pregnancies, including 17 with euploid fetuses, 5 discordant and 2 concordant for trisomy 21 and 1 discordant for trisomy 13 , and correctly classified all cases [20]. In the third study, cfDNA testing was carried out prospectively in 12 twin pregnancies, including 11 with euploid fetuses and 1 discordant for trisomy 21, and the correct classification was made in all cases [21].

Only one of the studies provided data on fetal fraction [20]. The total fetal fraction was measured; it was assumed that the contribution of each fetus was equal and it was estimated that each twin contributes about one third less cfDNA in maternal blood than in a singleton pregnancy. It was therefore suggested that reliable results from cfDNA testing in a twin pregnancy discordant for trisomy necessitates that the minimum total fetal fraction should be $6 \%$, rather than the $4 \%$ used in singleton pregnancies [20].

\section{Clinical Implications}

In the last 20 years the rate of twinning has increased, mainly due to the widespread use of assisted reproduction techniques and the increasing maternal age of the population. For example, in the USA and Canada the rates of twin live births increased from about 20 per 1,000 live births in 1991 to more than 30 in 2009 [22]. Most of the increase relates to dizygotic twins with major implications in terms of screening and diagnosis of aneuploidies and subsequent management of pregnancies discordant for such aneuploidies.

In dizygotic pregnancies, the maternal age-related risk for major trisomies for each twin may be the same as in singleton pregnancies and therefore the chance that at least 1 fetus is affected by a trisomy is twice as high as in singleton pregnancies. Furthermore, since the rate of dizygotic twinning increases with maternal age the proportion of twin pregnancies with trisomies is higher than in singleton pregnancies. Consequently, the proportion of twin pregnancies that are screen-positive by the traditional methods of screening is considerably higher than in singleton pregnancies.

The risk of miscarriage from invasive testing in twins is likely to be higher than in singletons [23]. If the pregnancies are discordant for an aneuploidy and the parents choose to have selective fetocide, the subsequent risk of miscarriage or early preterm delivery increases with gestational age at fetocide [24]. The risks of miscarriage from chorionic villus sampling and amniocentesis in twins are similar [25]. It is therefore preferable that in twin pregnancies screening for aneuploidies, invasive testing and when necessary selective fetocide are performed in the first rather than during the second trimester.

There is extensive evidence that in singleton pregnancies cfDNA analysis in maternal blood can lead to the detection of about $99 \%$ of fetuses with trisomy 21 at a false positive rate less than $0.1 \%$ and a no reporting rate of $2 \%$ from testing at 10-13 weeks $[1,15]$. The number of twin pregnancies undergoing cfDNA analysis in this and previous studies is too small to provide accurate assessment of the performance of the test. Nevertheless, it is likely that the sensitivity will be high and the false positive rate low. However, the high no reporting rate at first sampling is of major concern; this would shift the option of prenatal diagnosis and selective fetocide from the first to the second trimester with consequent increase in the rate 
of miscarriage. This problem is exemplified by one of our pregnancies discordant for trisomy 21 where selective fetocide at 15 weeks' gestation was followed by miscarriage at 20 weeks.

In twin pregnancies, the 11- to 13-week scan is essential for firstly, accurate determination of gestational age from the CRL of the largest fetus, secondly, diagnosis of major abnormalities that would allow for earlier and safer selective fetocide and thirdly, assessment of chorionicity which defines the risk for most pregnancy complications and therefore the subsequent management [26]. In twin pregnancies, as in singletons, there are essentially two options in the introduction of cfDNA testing in such a way as to retain the advantages of the 11- to 13-week scan $[15,27]$. One option is to carry cfDNA testing in all women at 10 weeks' gestation followed by a scan at 12 weeks; in patients with a high-risk score from cfDNA testing, invasive diagnostic testing and selective fetocide can be carried out in the first trimester. In cases with no result from cfDNA testing, pregnancy management could be based on the results of the combined test.
The alternative to universal screening by the cfDNA test is a strategy of cfDNA testing contingent on the results of first-line screening by ultrasound and biochemical testing. This approach retains the major advantages of cfDNA testing in increasing the detection rate of trisomies and decreasing the false positive rate, but at considerably lower cost than offering the test to the whole population [27]. The disadvantage of this approach, arising from delay or failure to obtain a result, is the resultant shift in diagnosis from the first to the second trimester. This could be partly ameliorated by offering invasive testing when the estimated risk from the combined test is very high and reserving cfDNA testing for the intermediate-risk group.

\section{Acknowledgements}

The study was supported by a grant from The Fetal Medicine Foundation (UK Charity No. 1037116). Analysis of stored plasma samples was performed at their own expense by Ariosa Diagnostics, 5945 Optical Court, San Jose, CA 95138, USA.

\section{References}

-1 Gil MM, Akolekar R, Quezada MS, Bregant B, Nicolaides KH: Analysis of cell-free DNA in maternal blood in screening for aneuploidies: meta-analysis. Fetal Diagn Ther, in press.

-2 Chiu RW, Akolekar R, Zheng YW, Leung TY, Sun H, Chan KC, Lun FM, Go AT, Lau ET, To WW, Leung WC, Tang RY, Au-Yeung SK, Lam H, Kung YY, Zhang X, van Vugt JM, Minekawa R, Tang MH, Wang J, Oudejans CB, Lau TK, Nicolaides KH, Lo YM: Non-invasive prenatal assessment of trisomy 21 by multiplexed maternal plasma DNA sequencing: large-scale validity study. BMJ 2011; 342:c7401.

-3 Ehrich M, Deciu C, Zwiefelhofer T, Tynan JA, Cagasan L, Tim R, Lu V, McCullough R, McCarthy E, Nygren AO, Dean J, Tang L, Hutchison D, Lu T, Wang H, Angkachatchai V, Oeth P, Cantor CR, Bombard A, van den Boom D: Noninvasive detection of fetal trisomy 21 by sequencing of DNA in maternal blood: a study in a clinical setting. Am J Obstet Gynecol 2011;204:205.e1-11.

$\checkmark 4$ Palomaki GE, Kloza EM, Lambert-Messerlian GM, Haddow JE, Neveux LM, Ehrich M, van den Boom D, Bombard AT, Deciu C, Grody WW, Nelson SF, Canick JA: DNA sequencing of maternal plasma to detect Down syndrome: an international clinical validation study. Genet Med 2011;13:913-920.

5 Sehnert AJ, Rhees B, Comstock D, de Feo E, Heilek G, Burke J, Rava RP: Optimal detec- tion of fetal chromosomal abnormalities by massively parallel DNA sequencing of cellfree fetal DNA from maternal blood. Clin Chem 2011;57:1042-1049.

6 Ashoor G, Syngelaki A, Wagner M, Birdir C, Nicolaides KH: Chromosome-selective sequencing of maternal plasma cell-free DNA for first-trimester detection of trisomy 21 and trisomy 18. Am J Obstet Gynecol 2012;206: 322.e1-5.

7 Qu JZ, Leung TY, Jiang P, Liao GJ, Cheng YK, Sun H, Chiu RW, Chan KC, Lo YM: Noninvasive prenatal determination of twin zygosity by maternal plasma DNA analysis. Clin Chem 2013;59:427-435.

8 Leung TY, Qu JZ, Liao GJ, Jiang P, Cheng YK, Chan KC, Chiu RW, Lo YM: Noninvasive twin zygosity assessment and aneuploidy detection by maternal plasma DNA sequencing. Prenat Diagn 2013;33:675-681.

-9 Struble CA, Syngelaki A, Oliphant A, Song K, Nicolaides KH: Fetal fraction estimate in twin pregnancies using directed cell-free DNA analysis.FetalDiagnTher,DOI:10.1159/000355653.

-10 Sepulveda W, Sebire NJ, Hughes K, Odibo A, Nicolaides KH: The lambda sign at 10-14 weeks of gestation as a predictor of chorionicity in twin pregnancies. Ultrasound Obstet Gynecol 1996;7:421-423.

11 Robinson HP, Fleming JE: A critical evaluation of sonar crown-rump length measurements. Br J Obstet Gynaecol 1975;182:702710 .
12 Nicolaides KH: Screening for fetal aneuploidies at 11 to 13 weeks. Prenat Diagn 2011;31: 7-15.

13 Wright D, Syngelaki A, Staboulidou I, Cruz Jde J, Nicolaides KH: Screening for trisomies in dichorionic twins by measurement of fetal nuchal translucency thickness according to the mixture model. Prenat Diagn 2011;31:16-21.

14 Madsen HN, Ball S, Wright D, Tørring N, Petersen OB, Nicolaides KH, Spencer K: A reassessment of biochemical marker distributions in trisomy 21-affected and unaffected twin pregnancies in the first trimester. Ultrasound Obstet Gynecol 2011;37:38-47.

15 Gil MM, Quezada MS, Bregant G, Ferraro M, Nicolaides $\mathrm{KH}$ : Implementation of maternal blood cell-free DNA testing in early screening for aneuploidies. Ultrasound Obstet Gynecol 2013;42:34-40.

-16 Sparks AB, Struble CA, Wang ET, Song K, Oliphant A: Noninvasive prenatal detection and selective analysis of cell-free DNA obtained from maternal blood: evaluation for trisomy 21 and trisomy 18. Am J Obstet Gynecol 2012;206:319.e1-9.

17 Snijders RJM, Sebire NJ, Cuckle H, Nicolaides $\mathrm{KH}$ : Maternal age and gestational age-specific risks for chromosomal defects. Fetal Diagn Ther 1995;10:356-367.

18 Snijders RJM, Sundberg K, Holzgreve W, Henry G, Nicolaides KH: Maternal age and gestation-specific risk for trisomy 21 . Ultrasound Obstet Gynecol 1999;13:167-170. 
19 Ashoor G, Syngelaki A, Poon LCY, Rezende JC, Nicolaides KH: Fetal fraction in maternal plasma cell-free DNA at 11-13 weeks' gestation: relation to maternal and fetal characteristics. Ultrasound Obstet Gynecol 20124; 1: 26-32.

20 Canick JA, Kloza EM, Lambert-Messerlian GM, Haddow JE, Ehrich M, van den Boom D, Bombard AT, Deciu C, Palomaki GE: DNA sequencing of maternal plasma to identify Down syndrome and other trisomies in multiple gestations. Prenat Diagn 2012;32:730734 .
21 Lau TK, Jiang F, Chan MK, Zhang H, Lo PS, Wang W: Non-invasive prenatal screening of fetal Down syndrome by maternal plasma DNA sequencing in twin pregnancies. J Matern Fetal Neonatal Med 2013;26:434-437.

22 Fell DB, Joseph KS: Temporal trends in the frequency of twins and higher-order multiple births in Canada and the United States. BMC Pregnancy Childbirth 2012;12:103-109.

23 Royal College of Obstetricians and Gynaecologists: Amniocentesis and Chorionic Villus Sampling. Green-Top Guideline No. 8. London, RCOG Press, 2010.

24 Evans MI, Goldberg JD, Dommergues M, Wapner RJ, Lynch L, Dock BS, Horenstein J, Golbus MS, Rodeck CH, Dumez Y, Holzgreve W, Timor Tritsch I, Johnson MP, Isada NB, Monteagudo A, Berkowitz RL: Efficacy of second-trimester selective termination for fetal abnormalities: International collaborative experience among the world's largest centers. Am J Obstet Gynecol 1994;171:90-94.
25 Agarwal K, Alfirevic Z: Pregnancy loss after chorionic villus sampling and genetic amniocentesis in twin pregnancies: a systematic review. Ultrasound Obstet Gynecol 2012;40: 128-134.

26 National Institute for Health and Clinical Excellence: Multiple pregnancy. NICE Clinical Guideline 129, 2011.

-27 Nicolaides KH, Syngelaki A, Poon LC, Gil M, Wright D: First-trimester contingent screening for trisomies 21,18 and 13 by biomarkers and maternal blood cell-free DNA testing. Fetal Diagn Ther 2014;35:185-192. 